\title{
DESENVOLVIMENTO DE SENSORES BIOELETRÔNICOS PARA QUALIFICAC̃̃̃O DE EXTRATOS ANTIOXIDANTES VEGETAIS DA REGIÃ̃O AMAZÔNICA
}

\author{
*N. M. BINDA ${ }^{1}$, R. S de AMORIM ${ }^{2}$, I. SOUZA ${ }^{3}$, W. R. BRITO ${ }^{4}$, R. R. PASSOS ${ }^{5}$, J. R.

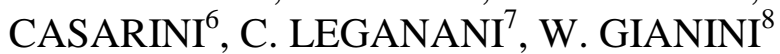 \\ ${ }^{1}$ Universidade do Estado do Amazonas, Escola Superior de Tecnologia \\ 2,3,4,5 Universidade Federal do Amazonas, Departamento de Química, \\ ${ }^{4,6}$ Laboratório de Caracterização de Circuitos Integrados, CT-PIM de Manaus, Amazonas \\ ${ }^{6}$ Instituto SENAI, Manaus, Amazonas \\ ${ }^{7,8}$ Universidade Federal de Juiz de Fora, Departamento de Física \\ *E-mail para contato: bindaneemias@gmail.com
}

\begin{abstract}
RESUMO - O presente trabalho tem como objetivo o desenvolvimento de sensores bioeletrônicos para qualificação de extratos antioxidantes vegetais da Região Amazônica. Estes sensores contribuem para a análise dentro do próprio ecossistema, permitindo uma exploração dos recursos de forma seletiva e sustentável. O sensor de trabalho conta com uma estrutura de dsDNA ancorada sobre uma nanoestrutura de $\mathrm{TiO} 2$ sobre uma sistema litografado de ITO/vidro de $2,1 \times 1,1 \mathrm{~cm}$. Foram realizados estudos envolvendo técnicas de voltametria cíclica seguindo a metodologia descrita por Jifeng Liu et al. As medidas voltamétricas foram realizadas após irradiação dos eletrodos com UV $254 \mathrm{~nm}$ em presença ou não do antioxidante. Os resultados demonstraram que a adição de antioxidante dificulta a fotodegradação do dsDNA, comprovando a factibilidade da estrutura proposta como sistema de quantificação das propriedades antioxidantes, assim como, a possibilidade na criação de um banco com os potenciais eletroquímicos obtidos.
\end{abstract}

\section{INTRODUÇÃO}

O sensor bioeletrônico é um instrumento integrado que é capaz de fornecer uma informação analítica específica, quantitativa ou semi-quantitativa, em tempo real, através do uso de um elemento de reconhecimento biológico (receptor bioquímico) que interage com um substrato alvo, a um transdutor físico, que converte os processos em sinais mensuráveis. Seu uso traz uma série de vantagens, pois são altamente sensíveis e seletivos, relativamente fáceis em termos de desenvolvimento, além de acessíveis e prontos para uso.

Estes instrumentos podem ser utilizados em diversas áreas, exercendo as mais variadas funções, como: análise ambiental em tempo real, executar controle em linha a nível industrial, 
automatização de análises bioquímicas, análise in vivo, detecção de substâncias biológicas relevantes (como hormônios e drogas).

Portanto, representam uma ferramenta promissora para suplementar as técnicas analíticas existentes, devendo ser analisadas as suas características únicas, tais como: Seletividade, Faixa de Sensibilidade, Precisão, Natureza da Solução, Tempo, Frequência de Amostragem, Estabilidade Operacional, Reprodutibilidade e Baixo Custo (SILVA et al., 2013).

\section{ESTRUTURA DE UM SENSOR BIOELETRÔNICO}

Conforme apresentado na figura 1, os sensores são construídos a partir de um componente que introduz a amostra, um sistema de reconhecimento molecular, um transdutor e uma unidade processadora de sinal (LEE et al, 2008).

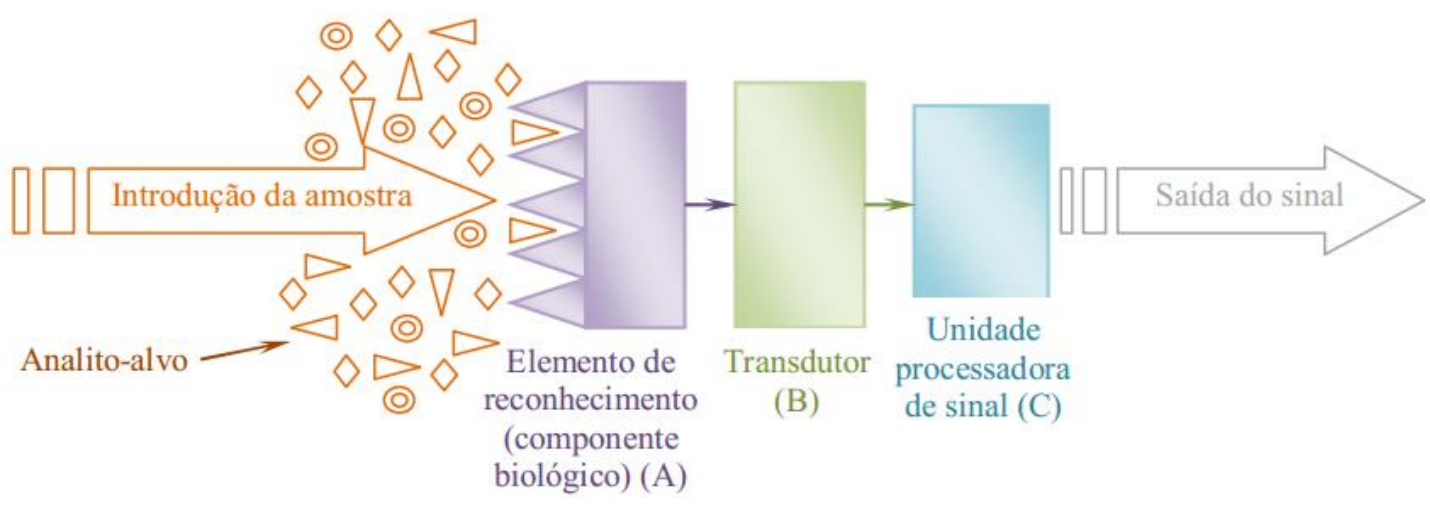

Figura 1 - Configuração de um sensor bioeletrônico, mostrando a organização dos seus componentes funcionais. A detecção do analito-alvo é feita por um componente biológico que gera um sinal (A), o qual é convertido (B) e processado (C).

O funcionamento de um sensor de uma forma geral envolve a especificidade e alta sensibilidade do componente biológico com o substrato de interesse. No sistema de reconhecimento está a parte que entra em contato com o analito de interesse e produz um sinal. Pode ser um receptor, enzima, anticorpo, ácido nucléico entre outros (PATHAK et al, 2007; CHAMBERS et al, 2008; LEE et al, 2008).

O transdutor age como uma interface, medindo a mudança física ou química que ocorre na reação com o biorreceptor, transformando essa energia em um produto mensurável, como massa, carga, calor ou luz. (MEHRVAR et al, 2000; PATHAK et al, 2007; LEE et al, 2008). Dos vários transdutores empregados na construção dos sensores, os mais utilizados são os eletroquímicos, óticos e calorimétricos

\subsection{Sensor Eletroquímico}

Essa classe de sensores se caracteriza por serem, simples, sensíveis, confiáveis, de resposta rápida, necessitam de instrumentação de baixo custo, operam em condições em que não é necessário um pré-tratamento da amostra e permitem efetuar determinações em uma 
ampla faixa de concentração. As técnicas eletrostáticas são capazes de fornecer limites de detecção excepcionalmente baixos e uma abundância de informações que caracterizam e descrevem eletroquimicamente determinados sistemas, sempre baseado nas propriedades elétricas de uma solução de analito quando ele está em contato com uma célula eletroquímica (MELO, 2008).

Tais informações incluem a estequiometria e a velocidade de transferência de carga interfacial, a velocidade de transferência de massa, a extensão de adsorção e de quimissorção e as velocidades e constantes de equilíbrio de reações químicas. Uma vantagem deste método é que células eletroquímicas são frequentemente específicas para um estado de oxidação particular e sua instrumentação é relativamente barata (MELO, 2008).

Dependendo do princípio de medição estes podem ser divididos em amperométricos, potenciométricos e condutimétricos.

\subsubsection{Sensores amperométricos}

Os sensores amperométricos são assim denominados devido ao seu mecanismo de transdução. O princípio de funcionamento é a medida da corrente produzida por uma reação química entre espécies eletroativas. Durante as medidas amperométricas, um potencial é mantido constante entre o eletrodo de trabalho (ET) e o eletrodo de referência (ER). A corrente gerada pela oxidação ou redução é diretamente proporcional à concentração das espécies eletroativas (SOARES, 2011).

\section{FOTOLITOGRAFIA}

A fotolitografia é um processo de transferência de padrões de uma máscara contendo um modelo para a superfície de um material sólido. Este processo exige condições controladas do ambiente como temperatura e umidade.

No processo fotolitográfico, um substrato é revestido com uma solução polimérica fotosensível (fotoresina) é posteriormente colocada uma máscara. A mascará definirá com precisão as áreas que serão abertas na superfície do substrato ao incidir com luz de determinado cumprimento de onda a máscara. Posteriormente é retirada a mascara e através do emprego de um revelador são dissolvidas as regiões expostas à fonte de luz. Dependendo do tipo de fotoresina empregado a litografia poderá ser positiva ou negativa. No exemplo anterior é tratada uma fotolitografia empregando uma fotoresina positiva (SEDRA, 2000).

\section{VOLTAMETRIA CÍCLICA}

A voltametria cíclica é a técnica mais comumente usada para adquirir informações qualitativas sobre os processos eletroquímicos. A eficiência desta técnica resulta de sua habilidade de rapidamente fornecer informações sobre a termodinâmica de processos redox, da cinética de reações heterogêneas de transferência de elétrons e sobre reações químicas acopladas a processos adsortivos (PACHECO, 2013). 
Inicia-se a aplicação do potencial de um valor no qual nenhuma redução ocorre, com o aumento do potencial para regiões mais negativas (catódica) ocorre a redução do composto em solução, gerando um pico de corrente proporcional à concentração deste composto, quando o potencial já tiver atingido um valor no qual nenhuma reação de redução ocorre, o potencial é varrido no sentido inverso, até o valor inicial, e no caso de uma reação reversível, os produtos que tiverem sido gerados no sentido direto (e se localizam ainda próximos à superfície do eletrodo) serão oxidados, gerando um pico simétrico ao pico da redução. O tipo de voltamograma gerado depende do tipo de mecanismo redox que o composto em questão sofre no eletrodo, o que faz da voltametria cíclica uma ferramenta valiosa para estudos mecanísticos (PACHECO, 2013).

\section{METODOLOGIA}

O sensor que deseja ser montado neste trabalhos conta com uma estrutura formada por três eletrodos litografados sobre substrato de ITO/vidro. As dimensões do dispositivo com os três eletrodos é de $2,1 \times 1,1 \mathrm{~cm}$. Uma camada de dsDNA ancorada sobre uma camada nanoestruturada de $\mathrm{TiO}_{2}$ como eletrodo de trabalho formando um sistema que se representa como dsDNA/TiO $/$ ITO. Foi testado a funcionalidade do sistema criado através da realização do teste de Voltametria Cíclica.

\section{RESULTADO E DISCUSSÃO}

A criação do sistema proposto começou a partir do desenvolvimento da base dos eletrodos, usando para a litografia uma foto-resina AZ-1518 e um revelador AZ-351 (Figura 2).

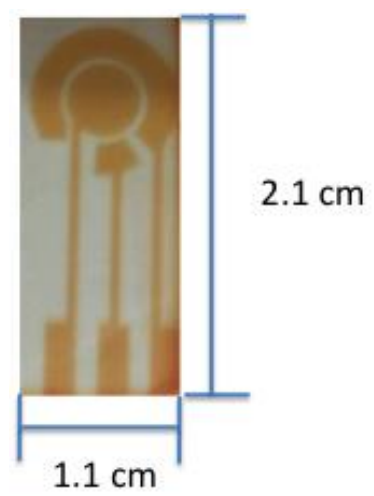

Figura 2. Litografia em ITO com uma foto-resina AZ-1518 e um revelador AZ-351 para o desenvolvimento da base dos eletrodos do sensor.

Sobre os eletrodos de referência e contra-eletrodo foi eletro-depositada uma camada de Níquel (Ni) e Platina(Pt) respectivamente. 
Em seguida, foi feito a formulação de uma camada de $\mathrm{TiO}_{2}$ nanoestruturada no eletrodo de trabalho (Figura 3a), para isto, foi depositada uma camada de sol-gel sob sistema de rotação (spin coating - $5000 \mathrm{rpm}$ por $5 \mathrm{~min}$ ). Neste sistema, por hidrólise ácida de isopropóxido de Titânio sobre filme de ITO depositado em substrato de vidro (adquirido comercialmente) a camada (eletrodo) foi formada. Posteriormente, o eletrodo foi calcinado em mufla por 30 minutos a $350{ }^{\circ} \mathrm{C}$, obtendo-se uma camada nanoestruturada de $\mathrm{TiO}_{2}$, com tamanho de partícula de $\mathrm{TiO}_{2}$ de $95,8 \mathrm{~nm}$ (determinado por método de dispersão da luz).

Posteriormente ancorada uma camada de dsDNA (Figura 3b). Para ancorar o DNA sobre o $\mathrm{TiO}_{2}$ a amostra foi submersa por 24 horas, em temperatura de $5{ }^{\circ} \mathrm{C}$, em solução de DNA com $\mathrm{ph}=4$ (DNA de bactérias rizomáticas). Após este procedimento o eletrodo foi lavado com água cuidadosamente. A imobilização do DNA foi confirmada através da utilização do brometo de etidio. O Brometo de etidio faz com que o DNA fique fluorescente quando exposto a luz UV. O sistema foi testado e confirmado a partir do uso de um espectro fotômetro UV-VIS da Thermo AquaMate 7000.

Ao final, foi obtido estrutura que deseja trabalhar, podendo ser descrita através do seguinte esquema: dsDNA/TiO $/$ /TTO.

Foram realizadas irradiação por 2 horas dos eletrodos com UV $254 \mathrm{~nm}$ (Figura 3c) em presença (Figura 3d) ou não do antioxidante (Figura 3e), em seguida foram medidas voltamétricas (Figura 3f) de cada sistema. Inicialmente foi empregada uma solução de cafeína, como agente antioxidante, para realizar estudos de estandardização através da comparação com anteriores publicações.

Os voltagramas foram obtidos empregando um potenciostato AutoLab 100 sendo o eletrodo de referência de $\mathrm{Ag} / \mathrm{AgCl}$ e o contra-eletrodo de Platina $(\mathrm{Pt})$. O eletrodo de trabalho DNA/TIO $/ 2$ ITO foi fixado adequadamente e submerso em solução de azul de metileno.

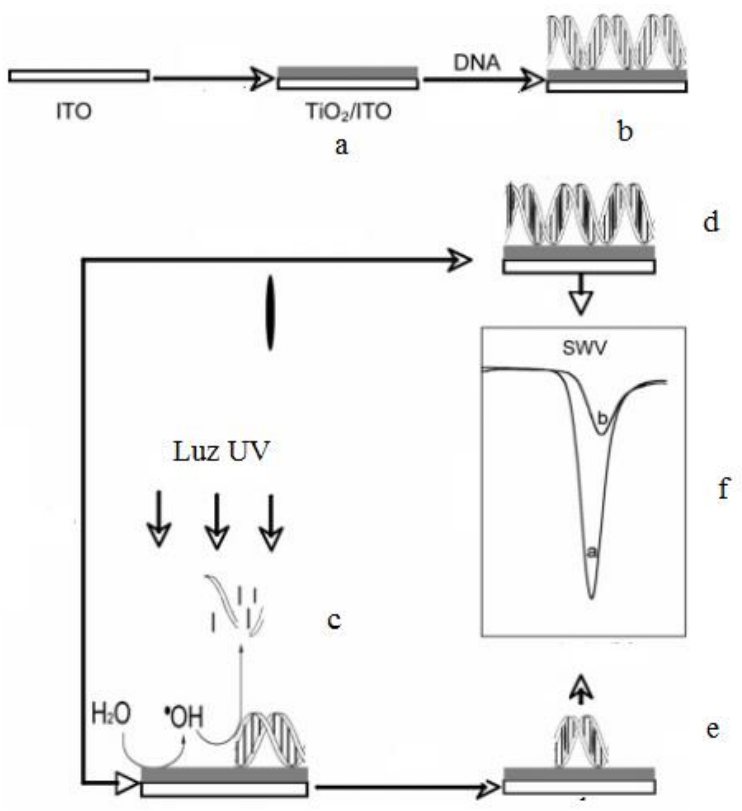


Figura 3 - Diagrama esquemático da montagem e funcionamento de um sensor dsDNA/TiO $/$ /ITO. a) Deposição de uma camada de $\mathrm{TiO}_{2}$ nanoestruturada; b) Ancoramento de uma camada de dsDNA; c) Irradiação de Luz UV; d) Sistema com antioxidante; e) Sistema sem-antioxidante; f) Realização da Voltametria Cíclica (LIU, 2005)

As medidas iniciais realizadas (Figura 4) mostram que os picos relacionados à oxidação do DNA decrescem com a presença do antioxidante. Assim, o que se observa é que a adição do antioxidante dificulta a degradação do DNA.

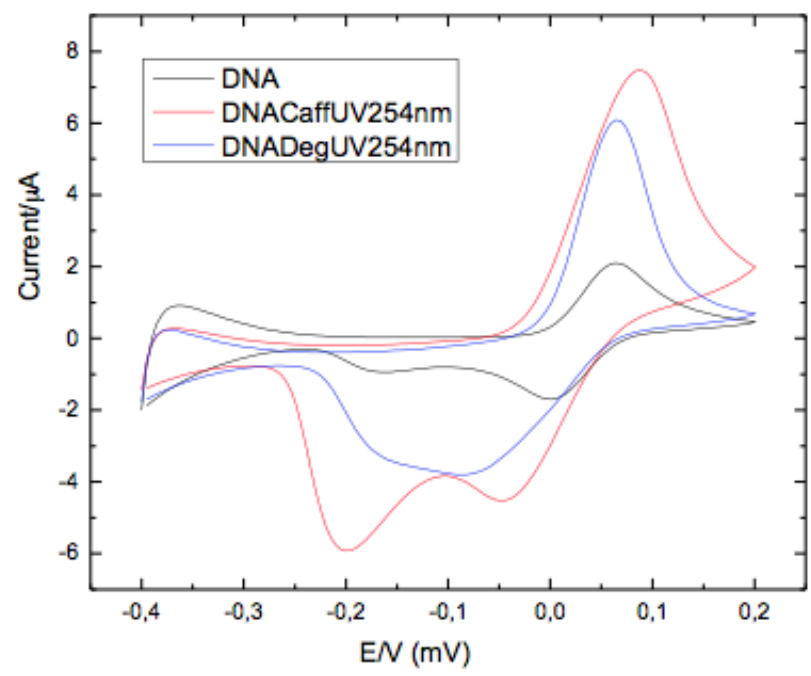

Gráfico 4 - Voltagramas do eletrodo DNA/TIO $2 /$ ITO em presencia de solução de cafeína.

\section{CONCLUSÃO}

Os resultados demonstraram que a adição de antioxidante dificulta a fotodegradação do dsDNA, comprovando a factibilidade da estrutura proposta como sistema de quantificação das propriedades antioxidantes, assim como, a possibilidade na criação de um banco com os potenciais eletroquímicos obtidos através da voltametria cíclica e a conformação de um banco de dados a partir dos resultados obtidos para o estudo de uma ampla variedade de extratos de plantas com potencial antioxidantes.

Possibilitou o desenvolvimento de habilidades dentro dos integrantes da equipe no relacionado à deposição de filmes finos, à imobilização da camada ativa, assim como à interpretação dos voltagramas. Estes resultados são complementados com medidas elétricas IV e estudos espectroscópicos.

\section{AGRADECIMENTOS}




\section{REFERÊNCIAS}

CHAMBERS, J. P. et al. Biosensor Recognition Elements. Curr. Issues Mol. Biol., v.10, p.1-12, 2008. L

LEE, Jeong-O et al. Aptamers as Molecular Recognition Elements for Electrical Nanobiosensors. Anal Bioanal Chem, v.390, p.1023 -1032, 2008.

LIU, J. Christophe Roussel; Gregoire Lagger, Philippe Tacchini, Hubert H. Girault. American Chemical Society, Analytical Chemistry. 2005.

MELO, A. F. Desenvolvimento Preliminar de um biosensor enzimático para determinação de Taninos hidrolisáveis. 2008 p 26.

PACHECO, W. F. SEMAAN, F. S.; ALMEIDA, V. G. K.; Ritta, A. G. S. L.; AUCÉLIO, R. Q. Voltametrias: Uma Breve Revisão Sobre os Conceitos. (2013)

PATHAK, P.; KATIYAR, V. K.; GIRI, S. Cancer Research - Nanoparticles, Nanobiosensors and Their Use in Cancer Research. AZojono Journal of Nanotechnology Online, v.3, set 2007.

SEDRA, A. S.; SMITH, K. C. Microeletrônica. São Paulo: Makron Books, 2000. P1270

SILVA, R. E. de O. et al. Aplicabilidade de um biossensor potenciômetro para análise de lipídeos em biodiesel de algodão "Gossypiumhirsutum L.” 2013.

SOARES , J. C. Biossensores e eletroquímicos fabricados a partir da imobilizacao da urease em filmes de polipirrol. 2011, p 27. 